\title{
CDKN2BAS gene polymorphisms and the risk of intracranial aneurysm in the Chinese population
}

Yunchang Chen ${ }^{1}$, Gancheng Li ${ }^{1}$, Haiyan Fan ${ }^{1}$, Shenquan Guo ${ }^{1}$, Ran Li ${ }^{1}$, Jian Yin ${ }^{1}$, Xin Zhang ${ }^{1}$, Xifeng Li, Xuying $\mathrm{He}^{1}$ and Chuanzhi Duan ${ }^{1,2^{*}}$

\begin{abstract}
Background: CDKN2BAS gene polymorphisms has been shown to correlation with intracranial aneurysm(IA) in the study of foreign people. The study, the author selected the Chinese people as the research object to explore whether CDKN2BAS gene polymorphisms associated with Chinese patients with IA.

Methods: We selected 200 patients(52.69 \pm 11.50$)$ with sporadic IA as experimental group, 200 participants(49. $99 \pm 13.00)$ over the same period to the hospital without cerebrovascular diseases as control group. Extraction of peripheral blood DNA, applying polymerase chain reaction(PCR)-ligase detection reaction (LDR) identified CDKN2BAS Single nucleotide polymorphism(SNP) locus genotype: rs6475606, rs1333040, rs10757272, rs3217992, rs974336, rs3217986, rs1063192. The differences in allelic and genotype frequencies between the patient and control groups were evaluated by the chi-square test or Fisher's exact tests.

Results: The genotype of rs1333040 and rs6475606 shown association with sporadic $\mid \mathrm{A}\left(X^{2}=8.545, P=0.014 ; X^{2}=10.961\right.$, $P=0.004$; respectively); the $C$ allele of rs6475606 showed reduction the occurrence of IA; the rs 1333040 and rs6475606 associated with hemorrhage, the C allele of rs 1333040 could lower the risk of hemorrhage, and rs6475606 will not, rs1333040 also associated with aneurysm size.

Conclusion: Our research shows that variant rs1333040 and rs6475606 of CDKN2BAS related to the Chinese han population of sporadic IAs occurs. This study confirms the association between CDKN2BAS and IAs.
\end{abstract}

Keywords: CDKN2BAS gene, Polymorphisms, Intracranial aneurysms

\section{Background}

IA is a complex disease affecting human health, it is the primary cause of subarachnoid hemorrhage. According to statistics, in the event of rupture of IA, patients' mortality and morbidity is 30 and $25 \%$, respectively. It is generally accepted that IA influenced both by genetic and environmental risk factors. Environmental factors including smoking, drinking, hypertension, diabetes and so on. Genetic factors, there are a number of human genes associated with the occurrence and development

\footnotetext{
*Correspondence: doctor_duanZJ@163.com

'Department of Neurosurgery, The National Key Clinic Specialty, The

Neurosurgery Institute of Guangdong Province, Guangdong Provincial Key

Laboratory on Brain Function Repair and Regeneration, Zhujiang Hospital,

Southern Medical University, Guangzhou 510282, China

${ }^{2}$ Department of Neurosurgery, Southern Medical University, Zhujiang

Hospital, 253\# industry road, Guangzhou, Guangdong 510282, China
}

of IA [1, 2, 22]. Genome-wide association study(GWAS) as a kind of method research on diseases, which applied to study of IA has found associated with these chromosomes:4q(EDNRA),5q31.3,6q24.2,8q12.1(SOX17), 9p21.3 (CDKN2A/CDKN2B/CDKN2BAS),10q24.32(CNNM2), 12q22,13q13.1(KL/STARD13), 18q11.2(RBBP8), 20p2.1 $[3,7,9,10,17,20,21]$.

CDKN2BAS located in chromosome 9p21, a $3.8 \mathrm{~kb}$ long non-coding RNA(lncRNA) expressed in the opposite direction from INK4A-ARF-INK4B gene cluster, it is associated with a variety of human diseases, such as prostate cancer, stomach cancer, pancreatic cancer, leukemia, glioma, colorectal cancer, lung cancer, diabetes and aneurysm $[4,5,14,16]$. There has been a lot of scholar studies supported CDKN2BAS gene multiple SNPs loci associated with IA. Hashikata confirmed 
rs1333040 associated with familial and sporadic IA in Japanese [8]. Foroud and his colleagues study United States population also confirmed CDKN2BAS SNP loci could lead to susceptibility of IA on the basis of predecessors' research results, and believe rs6475606 have significant effect on IA [6]; another research on Japanese found that rs 10757272 is a new susceptibility locus of IA, and confirmed rs10757278 associated with IA [13]; other chromosome gene polymorphism loci showed association with intracranial aneurysm, such as rs6841581(4q), rs12411886(10q), rs6538595(12q), rs9315204(13q), but the CDKN2BAS SNP loci were replicated successfully the most time in later studies [12, 21]. Due to the limitation of the study sample size, these studies credibility is not so high, the relationship between CDKN2BAS SNP loci and IA needs more study.

Whether CDKN2BAS SNP loci associated with China IAs patients has not been reported. Taking into account the same gene mutation rates is differ greatly in different populations and the genetic heterogeneity between races of people, so we use the database to find the minor allele frequency (MAF $\geq 0.05)$ of CDKN2BAS SNP loci at an $\mathrm{r}^{2}>0.8$ threshold in Chinese population, including rs3217992, rs974336, rs3217986, rs1063192, explore CDKN2BAS SNP effect on IAs, hope to provide new strategies for prevention and treatment of IAs.

\section{Methods}

\section{The research object}

This study was supported by Zhujiang Hospital of Southern Medical University ethics com- mittee, all the participants reported themselves to be of Han residents, have signed informed consent. Zhujiang Hospital is located in developed areas of China-Guangzhou, where the people from other provinces of China accounts for a large part of city population, and popul- ation flow is also very frequent, so the subjects of this study are representative. All particip- ants exclude genetic history, family history and history of malignancy, controlling the age between 18 and 80 years.

Within 14 months, this study recruited 200 patients with sporadic IAs, the median age was $52.69 \pm$ 11.50 years. Patients with IAs diagnosed by computed tomography angiography(CTA), magnetic resonance angiography(MRA) or digital subtraction angiography(DSA) has at least one aneurysm. For the diagnosis of hemorrhage caused by aneurysms, especially ruptured IAs, not only combined with clinical symptoms, but also confirmed by the DSA results eventually. All cases with confirmed IAs based on DSA were retrospectively reviewed by 2 independent doctors, a neuroradiologist and a neurosurgeon, they are all experienced in the diagnosis of aneurysms. All patients in the study underwent either craniotomy or interventional therapy to confirm the correct diagnosis of IAs again.

During the same period, 200 blood donors form a control group for the study, with a median age of $49.99 \pm 13.00$. Considering the prevalence of IAs vary between 0.2 and $9 \%$ of the population, this study does not recruit volunteers from the outside, control participants were patients(such as cerebral hemorrhage, cerebral trauma, epilepsy) from the Department of Neurosurgery of Zhujiang Hospital, as most of them have imaging data(computed tomography(CT), magnetic resonance imaging(MRI), MRA) and clinical information excluded the presence of aneurysms. Controls were eliminate diseases not only including polycystic kidney disease, Malaysia's syndrome, systemic lupus erythematosus (SLE), etc., but also severity of neurological diseases.

The subjects fully considered the balance and comparable of the baseline data during collection process, genomic DNA was extracted from Peripheral whole blood use kit, using agarose gel electrophoresis to detect the DNA integrity, ensure the follow-up test smoothly.

\section{Genotyping and SNP selection of CDKN2BAS}

Through foreign research literatures found the highest positive sites correlation with IAs, they are rs1333040, rs6475606, rs10757272; and using genetic database Hapmap (http://hapmap.org), Haploview (http://www.broad.mit.edu/ $\mathrm{mpg}$ /haploview) found the tagSNP loci of CDKN2BAS in Chinese population, including rs3217992, rs974336, rs3217986, rs1063192; so the seven sites as this research objects, SNP genotyping by PCR-LDR in Shanghai Biowing Applied Biotechnology Co., Ltd. The seven SNPs primer sequences and PCR length are given in Table 1; these SNPs probe sequences and LDR length are read in Table 2. PCR and LDR manipulated as previous describe [18], Firstly, PCR amplification of SNP sites in 20ul master mix, containing 2ul $1 \times$ buffer, $0.6 \mathrm{ul} \mathrm{Mg++}$, 2ul dNTPs, $0.2 \mathrm{ul}$ Taq polymerase, $4 \mathrm{ul} 1 \times$ Q-solution, $0.4 \mathrm{ul}$ primer mix and $9.8 \mathrm{ul} \mathrm{ddH}^{2} \mathrm{O}$, after thoroughly incorporated, take $19 \mathrm{ul}$ partial shipments in PCR reaction tube and add 1ul genomic DNA of samples, set the following program on Gene Amp PCR system (model 9600, Perkin Elmer): denaturing at $95^{\circ} \mathrm{C}$ for $15 \mathrm{~min}$; then denaturing at $94{ }^{\circ} \mathrm{C}$ for $30 \mathrm{~s}$, annealing at $56{ }^{\circ} \mathrm{C}$ for $1 \mathrm{~min}$, extension at $72{ }^{\circ} \mathrm{C}$ for $1 \mathrm{~min}$, repeat 35 cycles; also need to extend 7 min under $72{ }^{\circ} \mathrm{C}$ temperature. Secondly, LDR performed to further amplification in 10ul volume of Multiplex LDR mixture, before operation LDR add the same as volume $\mathrm{ddH}^{2} \mathrm{O}$ to $\mathrm{PCR}$ amplification product, the LDR mixture containing resultant PCR product of $1 \mathrm{ul}, 1 \mathrm{ul}$ probe mix, $0.05 \mathrm{ul}$ Taq DNA ligase,

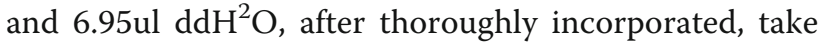
9ul partial shipments in PCR reaction tube and add 1ul PCR amplification product, set LDR conditions: initial denaturing at $95{ }^{\circ} \mathrm{C}$ for $2 \mathrm{~min}$, followed by 
Table 1 Primer sequences and PCR length

\begin{tabular}{llll}
\hline Primer name & sequence(5-3) up & low & PCR length \\
\hline rs1333040 & TAATGGGATGAGTGCAGGG & AACCTCCATGAGAACTGGCT & 193 \\
rs3217986 & CTCCACCAGATAGCAGAGGG & CCACCACCTCATCCTGTGTA & 176 \\
rs10757272 & CCTGAGGAGAAGAGAAGGGC & TGGGGCACATGATTCCAAAA & 180 \\
rs6475606 & AAAGGAAGAACATGGCACCC & TTGTAGAACACAACAACCCC & 87 \\
rs1063192 & GTGTAATATAGTACTGTGGG & CTTGTGGAATCTTCCTAAT & 85 \\
rs974336 & CAGACATCAGAGACCTGAAC & GCAGGTGGAGCCATTAAAG & 78 \\
rs3217992 & GGAATTAATTITACATGGC & TGGGTATCAATTACCACCTG & 67 \\
\hline
\end{tabular}

35 cycles of denaturing at $94{ }^{\circ} \mathrm{C}$ for $30 \mathrm{~s}$, and annealing at $50{ }^{\circ} \mathrm{C}$ for $2 \mathrm{~min}$, mix 1 ul of LDR product with 0.6ul ROX(ABI.GS-500), after denaturing at $95{ }^{\circ} \mathrm{C}$ for $2 \mathrm{~min}$, in the ice cold snap, following capillary electrophoresis, meanwhile applying Genemapper(ABI, Inc.) for data analysis and genotyping.

\section{Statistical analysis}

Hardy-Weinberg equilibrium tested by chi-square in control, allelic and genotype frequencies are evaluated by chi-square test or Fisher's exact tests, all data analysis using SPSS 20.0, considering statistical differences when $P$ value is less than 0.05 .

\section{Results}

Clinical background of patients

The clinical information of the study participants was summarized in Table 3. Female patients with IAs accounted for $61.5 \%$, is 1.60 times of male patients, and consistent with other related reports $[18,23]$. The baseline data balanced between the experimental group and the control group, including gender, smoking, drinking, hypertension and diabetes. Patients with IAs also make specific statistic about aneurysm number and position. There were 90 patients with IAs located in the posterior communicating artery and internal carotid artery, 41 patients in the anterior cerebral artery and 32 patients in posterior cerebral artery. The numbers of patients with

Table 2 Probe sequences and LDR length

\begin{tabular}{|c|c|c|}
\hline Probename & sequence(5-3) & LDR length \\
\hline rs1333040_modify & P-CATTCTTACCTCTGACCCTCTITIITITTITITITT-FAM & \\
\hline rs1333040_C & TIIITITITाTाTाCTTCCTCTCTGTCCCAGCGGTAG & 77 \\
\hline rs1333040_T & TITITITITITाTाTTCTTCCTCTCTGTCCCAGCGGTAA & 79 \\
\hline rs3217986_modify & P-СCTCTCTTACCCCTCTGCTATITITITITITITIITITIT-FAM & \\
\hline rs3217986_A & TITITITITITITITTAGCATCTGTCGTCGCTTGCACAT & 82 \\
\hline rs3217986_C & TIITITITITITIITITAGCATCTGTCGTCGCTTGCACAG & 84 \\
\hline rs10757272_modify & P-CTTCTTACGACCTITCATAATTITITITITITITITITITIT-FAM & \\
\hline rs10757272_C & TITITTTITTTITITITTATAATAAAACATTGCAACATTCG & 87 \\
\hline rs10757272_T & 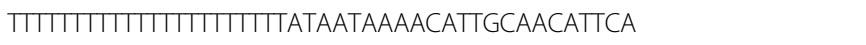 & 89 \\
\hline rs6475606_modify & P-CTTTCACTGAGTGTCCATTATTITITITITITITITITITTITITT-FAM & \\
\hline rs6475606_C & 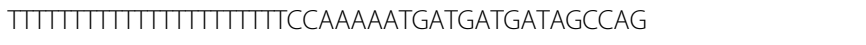 & 92 \\
\hline rs6475606_T & TाITाTाताTाTाTाTाTाTाTCCAAAAATGATGATGATAGCCAA & 94 \\
\hline rs1063192_modify & P-GTTGTCATTAGGAAAGATTCTITITITITITITITITITITITITITIT-FAM & \\
\hline rs1063192_C & TITITITITITITITITITITCTITAGTTTCCCTTAATATCAG & 97 \\
\hline rs1063192_T & TIITITITITITITITITITITTCTTAAGTTTCCCTTAATATCAA & 99 \\
\hline rs974336_modify & 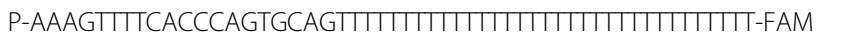 & \\
\hline rs974336_A & 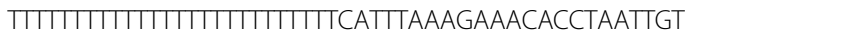 & 102 \\
\hline rs974336_G & TIIIIIIIITाITाIIIIIIIITTCATTAAAAGAAACACCTAATTGC & 104 \\
\hline rs3217992_modify & 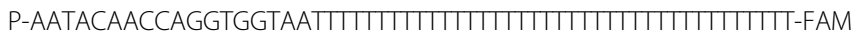 & \\
\hline rs3217992_A & TITITITITITITITITITITITTGGGCATTGATAAGTTACTATTT & 107 \\
\hline rs3217992_G & 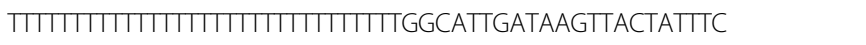 & 109 \\
\hline
\end{tabular}


Table 3 Characteristics of patients with IAs vs. controls

\begin{tabular}{|c|c|c|c|c|}
\hline & Aneurysms group & Controls group & $X^{2}$ value & $P$ value \\
\hline Number & 200 & 200 & & \\
\hline Male & $77(38.5)$ & 78(39.0) & & \\
\hline Female & $123(61.5)$ & $122(61.0)$ & 0.011 & 0.918 \\
\hline Age & $52.69 \pm 11.50$ & $49.99 \pm 13.00$ & 1.639 & 0.201 \\
\hline Smoking & $43(21.5)$ & $40(20.0)$ & & \\
\hline Non-smoking & 157(78.5) & 160(80.0) & 0.137 & 0.711 \\
\hline Drinking & $44(22.0)$ & $42(21.0)$ & & \\
\hline Non-drinker & 156(78.0) & 158(79.0) & 0.059 & 0.808 \\
\hline Hypertension & $59(29.5)$ & $54(27.0)$ & & \\
\hline Non-hypertension & $141(70.5)$ & 146(73.0) & 0.308 & 0.579 \\
\hline Diabetes & $24(12.0)$ & $22(11.0)$ & & \\
\hline Non-diabetes & 176(88.0) & 178(89.0) & 0.098 & 0.754 \\
\hline \multicolumn{5}{|l|}{ Site of aneurysm(\%) } \\
\hline ACA & $41(20.5)$ & & & \\
\hline PCA & $32(16.0)$ & & & \\
\hline $\mathrm{ACOA}$ & $16(8.0)$ & & & \\
\hline ICA,PCOA & $90(45.0)$ & & & \\
\hline MCA & $10(5.0)$ & & & \\
\hline other & $11(5.5)$ & & & \\
\hline \multicolumn{5}{|c|}{ Number of aneurysm(319) } \\
\hline One & $130(65.0)$ & & & \\
\hline Two & $35(17.5)$ & & & \\
\hline Three & $21(10.5)$ & & & \\
\hline$>$ three & $14(7.0)$ & & & \\
\hline
\end{tabular}

$A C A$ anterior cerebral artery, $A C O A$ anterior communicating artery, ICA internal carotid artery, $M C A$ middle cerebral artery, $P C A$ posterior cerebral artery, $P C O A$ posterior communicating artery

Fig. 1 Two loci of the gene-picture


one aneurysm, two aneurysms, three aneurysms, more than 3 aneurysms are 130,35, 21, 14 respectively.

\section{Allelic association study with SNPs of CDKN2BAS}

We randomly selected two loci of the Genemapper as shown in Fig. 1. The genotype and allele frequency of cases and controls was presented in Table 4. The control group completely accorded with Hardy-Weinberg equilibrium and objects included in the study could represent the crowd finely. The difference in seven sites of genotype and allele frequency was compared with chisquare or Fisher's exact tests. The genotype frequency of rs6475606 show significant difference between cases and $\operatorname{controls}\left(\mathrm{X}^{2}=10.961, P=0.004\right)$, There also existed difference among groups when compared frequency of TT with CC and CT genotypes combined $\left(\mathrm{X}^{2}=9.008\right.$, OR 1.831 [95\% confidence interval $1.232-2.723$ ] $P=0.003$ ), the $C$ allele showed reduction the risk of $\operatorname{IAs}\left(\mathrm{X}^{2}=4.784\right.$, OR 0.710 [95\% confidence interval 0.522-0.966], $P=$ 0.029). The distribution of the variants rs1333040 was significantly different in genotype frequency among cases and controls $\left(\mathrm{X}^{2}=8.545, P=0.014\right)$, and compared frequency of TT with CC and CT genotypes combined, the results were significant $\left(\mathrm{X}^{2}=7.295\right.$, OR $1.722[95 \%$ confidence interval 1.159-2.558], $P=0.007$ ).

\section{Genotype is related to clinical manifestation}

The study aimed to assess the correlation between CDKN2BAS SNP genotypes and clinical presentation(such as hemorrhage, epilepsy, aneurysm location and size) of

Table 4 genotype and allele frequencies of patients with IAs vs. controls

\begin{tabular}{|c|c|c|c|c|c|c|}
\hline & & Aneurysms & Controls & $X^{2}$ value & $P$ value & OR(95\%Cl) \\
\hline \multirow[t]{4}{*}{ rs1333040 } & CC & $19(9.5)$ & 18(9) & 8.545 & 0.014 & \\
\hline & CT & $65(32.5)$ & $92(46)$ & & & \\
\hline & $\pi$ & $116(58)$ & $90(45)$ & & & \\
\hline & $\mathrm{CC}+\mathrm{CT}$ & $84(42)$ & $111(55.5)$ & 7.295 & 0.007 & $1.722(1.159-2.558)$ \\
\hline C allele & & 103/297(25.75) & $128 / 272(32)$ & 3.804 & 0.051 & $0.737(0.542-1.002)$ \\
\hline \multirow[t]{4}{*}{ rs3217986 } & AA & $166(83)$ & 157(78.5) & 1.597 & 0.445 & \\
\hline & $A C$ & $32(16)$ & $39(19.5)$ & & & \\
\hline & $\mathrm{CC}$ & $2(1)$ & $4(2)$ & & & \\
\hline & $A C+C C$ & $34(17)$ & $43(21.5)$ & 1.303 & 0.254 & $0.748(0.454-1.233)$ \\
\hline \multirow[t]{4}{*}{ rs10757272 } & $\mathrm{CC}$ & $21(10.5)$ & $22(11)$ & 0.497 & 0.780 & \\
\hline & $\mathrm{CT}$ & $97(48.5)$ & $90(45)$ & & & \\
\hline & $\pi$ & $82(41)$ & $88(44)$ & & & \\
\hline & $\mathrm{CC}+\mathrm{CT}$ & $112(56)$ & $111(55.5)$ & 0.368 & 0.544 & $1.131(0.760-1.681)$ \\
\hline \multirow[t]{4}{*}{ rs6475606 } & CC & $19(9.5)$ & $17(8.5)$ & 10.961 & 0.004 & \\
\hline & $\mathrm{CT}$ & $63(31.5)$ & $95(47.5)$ & & & \\
\hline & $\pi$ & $118(59)$ & $88(44)$ & & & \\
\hline & $\mathrm{CC}+\mathrm{CT}$ & $82(41)$ & $112(56)$ & 9.008 & 0.003 & $1.831(1.232-2.723)$ \\
\hline C allele & & 101/299(25.25) & 129/271(32.25) & 4.784 & 0.029 & $0.710(0.522-0.966)$ \\
\hline \multirow[t]{4}{*}{ rs1063192 } & CC & $6(3)$ & $5(2.5)$ & 0.783 & 0.676 & \\
\hline & $C T$ & $56(28)$ & $49(24.5)$ & & & \\
\hline & $\pi$ & $138(69)$ & $146(73)$ & & & \\
\hline & $C C+C T$ & $62(31)$ & $54(27)$ & 0.777 & 0.378 & $1.215(0.788-1.872)$ \\
\hline \multirow[t]{4}{*}{ rs974336 } & AA & $9(4.5)$ & $3(1.5)$ & 3.983 & 0.137 & \\
\hline & $A G$ & $63(31.5)$ & $74(37)$ & & & \\
\hline & GG & $128(64)$ & $123(61.5)$ & & & \\
\hline & $A A+A G$ & $72(36)$ & $77(38.5)$ & 0.267 & 0.605 & $0.899(0.599-1.348)$ \\
\hline \multirow[t]{4}{*}{ rs3217992 } & AA & $61(30.5)$ & $60(30)$ & 1.021 & 0.600 & \\
\hline & $A G$ & $101(50.5)$ & $94(47)$ & & & \\
\hline & GG & $38(19)$ & $46(23)$ & & & \\
\hline & $A G+G G$ & $139(69.5)$ & $140(70)$ & 0.012 & 0.913 & $0.977(0.637-1.496)$ \\
\hline
\end{tabular}


aneurysms(Table 5). Statistical analysis indicated that both of rs1333040 and rs6475606 were associated with hemorrhage. The $\mathrm{C}$ allele of rs1333040 reduced the incidence of hemorrhage. The $C$ allele of rs6475606 was overrepresented in controls which controversial with it was the risk of hemorrhage $\left(\mathrm{X}^{2}=9.626\right.$, OR 2.002 [95\% confidence interval 1.286-3.119], $P=0.002$ ); and rs13330 40 also related to aneurysm $\operatorname{size}(P<0.000)$, the $C$ allele was the risk factor of IAs with size $<3 \mathrm{~cm}\left(\mathrm{X}^{2}=7.358\right.$, OR 2.020 [95\% confidence interval 1.207-3.380], $P=0.007$ ). The study did not find that CDKN2BAS SNP genotypes was associated with epilepsy and aneurysm location.

\section{Discussion}

In this study, we aim to explore CDKN2BAS genetic relationship with Chinese han nationality of IAs. We provided evidence that the variants rs1333040 and rs6475606 were associated with IAs, in agreement with the results of Hashikata et al. and Foroud et al., respectively. Hashikata et al. based on previous results of Genome-wide association studies(GWAS) confirmed rs1333040 association with familial and sporadic IAs in Japanese patients, their study included 419 sporadic IA cases and 408 control subjects; Foroud et al. utilized the similar approach to investigate the role of rs6475606 in 1095 IA cases and 1286 controls, as the size of the sample, our results with theirs differ markedly.

Rs3217992, rs974336, rs3217986, rs1063192 are the highest mutation rate locus of CDKN2BAS gene in
Chinese population. We can learn from the Table 4 that the four sites genotype frequency and allele frequency were close in the experimental group and the control group. Statistical results show that these loci loss correlation with sporadic IAs of China(all $P$ values $>0.05$ ), rs6475606, rs1333040 and rs10757272 are the highest positive sites correlation with IAs in overseas study,reflect the Japan and the United States population, rs1333040 and rs6475606 were also replicated, but no association of the variant rs10757272 with sporadic IAs was found in our study, the conflicting results mainly root in genetic heterogeneity in different ethnic populations, additionally, the presence of genetic heterogeneity may be relevant in a bias caused by variation in the prevalence of a positive family history between populations, because familial IAs have a higher risk than sporadic IAs, negative results for this SNP do not exclude CDKN2BAS SNP plays an important role in aneurysms. The other four loci selected in this study which is the highest mutation rates in Chinese population were unrelated to aneurysms, among previous studies, a research thinks disease-causing mutations may be located in $\mathrm{MAF}<0.05$, and influence the formation of IAs. We also detected statistically significant correlations between CDKN2BAS SNPs and hemorrhage and aneurysm size, rs1333040_C did not work in aneurysm formation, but it could reduce the occurrence of hemorrhage and it was the risk factor of IAs with size $<3 \mathrm{~cm}$; the rs6475606_C could reduce the occurrence of IAs, but the impact of it on hemorrhage and size was not clear, the reason may be related to the research errors.

Table 5 Analysis of genotype and clinical presentation

\begin{tabular}{|c|c|c|c|c|c|c|}
\hline & & $\begin{array}{l}\text { Hemorrhage } \\
\text { (136 patients) }\end{array}$ & $\begin{array}{l}\text { No Hemorrhage } \\
\text { (64 patients) }\end{array}$ & $x^{2}$ value & $P$ value & $\mathrm{OR}(95 \% \mathrm{Cl})$ \\
\hline \multirow[t]{3}{*}{ rs1333040 } & CC & 14(10.29) & $5(7.80)$ & & & \\
\hline & $C T$ & $31(22.79)$ & $34(53.13)$ & 18.421 & $0.000^{*}$ & \\
\hline & $\pi$ & $91(66.92)$ & 25(39.07) & & & \\
\hline C allele & & $59 / 272(21.69)$ & 44/128(34.38) & 4.182 & 0.041 & $0.631(0.405-0.983)$ \\
\hline \multirow[t]{3}{*}{ rs6475606 } & CC & 13(9.56) & $6(9.38)$ & & & \\
\hline & $C T$ & $26(19.12)$ & $37(57.81)$ & 31.628 & $0.000^{*}$ & \\
\hline & $\pi$ & $97(71.32)$ & $21(32.81)$ & & & \\
\hline \multirow[t]{2}{*}{ C allele } & & $52 / 272(22.43)$ & 49/128(31.25) & 9.626 & 0.002 & $2.002(1.286-3.119)$ \\
\hline & & $\begin{array}{l}\operatorname{Size}(\geq 3 \mathrm{~cm}) \\
\text { ( } 72 \text { patients) }\end{array}$ & $\begin{array}{l}\text { Size }(<3 \mathrm{~cm}) \\
\text { (128 patients) }\end{array}$ & $x^{2}$ value & $P$ value & \\
\hline \multirow[t]{3}{*}{ rs1333040 } & $\mathrm{CC}$ & $8(11.11)$ & $11(8.59)$ & & & \\
\hline & $C T$ & $6(8.33)$ & $57(44.53)$ & 28.355 & $0.000^{*}$ & \\
\hline & $\Pi$ & $58(80.56)$ & $60(46.88)$ & & & \\
\hline$C$ allele & & 22/144(15.28) & 79/256(30.86) & 7.358 & 0.007 & $2.020(1.207-3.380)$ \\
\hline \multirow[t]{3}{*}{ rs6475606 } & CC & $7(9.72)$ & $12(9.37)$ & & & \\
\hline & $C T$ & 23(31.94) & $40(31.25)$ & 0.021 & 0.989 & \\
\hline & $\pi$ & $42(58.33)$ & $76(59.38)$ & & & \\
\hline
\end{tabular}


The sequence of CDKN2BAS gene is so long that it will be very difficult to find the exact loci associated with IA. Rs6475604, rs1333040, rs10757272 associated with IA come from GWAS mostly, these loci are not for more research, and lack of functional studies. IA is a complex genetic disease, the interaction between genes and genes as racial differences will affect the results of our study. CDKN2BAS belongs to long noncoding RNA(lncRNA) and affects the surrounding gene expression indirectly play a role in the disease, Bai Y research results show that CDKN2BAS can regulate the expression of CARD8 level, which affects the progress of atherosclerosis, compare the RNA in aneurysm tissue and normal cerebrovascular, hundreds of lncRNA exists differences, we can't help but question: would CDKN2BAS cause IA formation? Or CDKN2BAS associated with IA could be caused by other lncRNA $[2,15,19]$.

The current generally accepted IA is the result of the dual role of genetic and environmental factors, screening finds a large number of genes associated with IA, but these genes effect on IA is too low, thus known that the influence of environmental factors on the disease may be greater, CDKN2BAS gene polymorphism correlated with IA in other population, but has nothing to do with the Chinese people, there is a hypothesis: the environment makes IA more susceptible to CDKN2BAS in other population, although rs3217992, rs974336, rs3217986 and rs1063192 are the highest mutation rate loci of CDKN2BAS gene in Chinese population, influenced by environmental factors, they without associated with IA [11].

In addition to the above mentioned several assumptions, our study associated with the degree and distribution of linkage disequilibrium [1]. Research work in susceptibility genes of IA did not make substantive progress, scholars have been staying at the screening level, but many of genes repeatability is poor, the author considers not all IA are related to gene mutation, genetic, environmental and perhaps many other factors involved in the IA progress, it needs us to further research.

\section{Conclusions}

Our study showed that CDKN2BAS polymorphism might be associated with intracranial aneurysms in Chinese population. Additional studies are needed to confirm our finding.

\footnotetext{
Abbreviations

ACA: Anterior cerebral artery; ACoA: Anterior communicating artery; $\mathrm{Cl}$ : Confidence intervals; CTA: Computed tomography angiography; DSA: Digital subtraction angiography; GWAS: Genome-wide association study; IA: Intracranial aneurysm; ICA: Internal carotid artery; LDR: Ligase detection reaction; IncRNA: long noncoding RNA; MAF: Minor allele frequency; MCA: Middle cerebral artery; MRA: Magnetic resonance angiography; MRI: Magnetic resonance imaging; OR: Odds ratio; PCA: Posterior cerebral artery; PCoA: Posterior communicating artery; PCR: Polymerase chain reaction; SNP: Single nucleotide polymorphism
}

\section{Acknowledgments}

We thank the DNA donors and the supporting medical staff for making this study possible.

\section{Funding}

The authors report no conflict of interest concerning the materials or methods used in this study or the findings specified in this paper. This study was supported by the National Natural Science Foundation of China (Grants No.81271315), National Key Research Development Program (Grants No.2016YFC1300804,2016YFC1300800), Specialized Research Fund for the Doctoral Program of Higher Education (Grants No.20124433110014). The funders had no role in study design, data collection and analysis, decision to publish, or preparation of the manuscript.

\section{Availability of data and materials}

individual data is stored by the corresponding author. The raw data generated and/or analyzed during the current study are not publicly available due to the fact that consent was obtained to provide only cumulative anonymized data but are available from the corresponding author on reasonable request.

\section{Authors' contributions}

Author contributions to the study and manuscript preparation include the following. Conception and design: YCC. Acquisition of data: YCC, SQG. Drafting the article: YCC, XZ, HYF. Critically revising the article: all authors. Reviewed submitted version of manuscript: all authors. Statistical analysis: YCC, CZD. Study supervision: CZD, YCC. Approved the final version of the manuscript on behalf of all authors.

\section{Ethics approval and consent to participate}

The study was approved by the Ethical Committees of Zhujiang Hospital of Southern Medical University. All participants volunteered to be part of the activity after informed the purpose and significance of the study and signed the informed consent form, the blood samples obtained from this study were from volunteers who signed informed consent.

\section{Consent for publication}

Consent for data sharing and publication was obtained as part of the informed consent form.

\section{Competing interests}

The authors declare that they have no competing interests.

\section{Publisher's Note}

Springer Nature remains neutral with regard to jurisdictional claims in published maps and institutional affiliations.

Received: 26 July 2017 Accepted: 22 November 2017

Published online: 11 December 2017

References

1. Adeyemo A, Rotimi C. Genetic variants associated with complex human diseases show wide variation across multiple populations. Public Health Genomics. 2010;13(2):72-9. doi:10.1159/000218711.

2. Bai $Y$, Nie S, Jiang G, Zhou Y, Zhou M, Zhao Y, et al. Regulation of CARD8 expression by ANRIL and association of CARD8 single nucleotide polymorphism rs2043211 (p.C10X) with ischemic stroke. Stroke. 2014;45(2): 383-8, doi:10.1161/STROKEAHA.113.003393.

3. Bilguvar K, Yasuno K, Niemelä M, Ruigrok YM, von Und Zu Fraunberg M, van Duijn CM, et al. Susceptibility loci for intracranial aneurysm in European and Japanese populations. Nat Genet. 2008;40(12):1472-7. doi:10.1038/ng.240.

4. Bochenek G, Hasler R, El Mokhtari NE, Konig IR, Loos BG, Jepsen S, et al. The large non-coding RNA ANRIL, which is associated with atherosclerosis, periodontitis and several forms of cancer, regulates ADIPOR1, VAMP3 and C11ORF10. Hum Mol Genet. 2013;22(22):4516-27. doi:10.1093/hmg/ddt299.

5. Broadbent HM, Peden JF, Lorkowski S. Susceptibility to coronary artery disease and diabetes is encoded by distinct, tightly linked SNPs in the ANRI locus on chromosome 9p. Hum Mol Genet. 2008;17(6):806-14.

6. Foroud T, Koller DL, Lai D, Sauerbeck L, Anderson C, Ko N, et al. Genomewide association study of intracranial aneurysms confirms role of Anril and 
SOX17 in disease risk. Stroke. 2012;43(11):2846-52. doi:10.1161/STROKEAHA. 112.656397.

7. Foroud T, Lai D, Koller D, Van't Hof F, Kurki Ml, Anderson CS, et al. Genomewide association study of intracranial aneurysm identifies a new association on chromosome 7. Stroke. 2014;45(11):3194-9. doi:10.1161/STROKEAHA.114. 006096.

8. Hashikata H, Liu W, Inoue K, Mineharu Y, Yamada S, Nanayakkara S, et al. Confirmation of an Association of Single-Nucleotide Polymorphism rs1333040 on 9p21 with familial and sporadic intracranial aneurysms in Japanese patients. Stroke. 2010;41(6):1138-44. doi:10.1161/STROKEAHA.109. 576694.

9. Helgadottir A, Thorleifsson G, Magnusson KP, Grétarsdottir S, Steinthorsdottir V, Manolescu A, et al. The same sequence variant on 9p21 associates with myocardial infarction, abdominal aortic aneurysm and intracranial aneurysm. Nat Genet. 2008:40(2):217-24.

10. Holdt LM, Teupser D. Recent studies of the human chromosome 9p21 locus, which is associated with atherosclerosis in human populations. Arterioscler Thromb Vasc Biol. 2012;32(2):196-206. doi:10.1161/ATVBAHA.111. 232678.

11. Hunter DJ. Gene-environment interactions in human diseases. Nat Rev Genet. 2005;6(2):287-98.

12. Koichi Akiyama ANHN, Atsushi Tajima BKKY. Genome-wide association study to identify genetic variants present in Japanese patients harboring intracranial aneurysms. J Hum Genet. 2010;55(10):656-61. doi:10.1038/jhg. 2010.82.

13. Low SK, Takahashi A, Cha PC, Zembutsu H, Kamatani N, Kubo M, et al. Genome-wide association study for intracranial aneurysm in the Japanese population identifies three candidate susceptible loci and a functional genetic variant at EDNRA. Hum Mol Genet. 2012;21(9):2102-10. doi:10.1093/ $\mathrm{hmg} / \mathrm{dds} 020$.

14. Nie FQ, Sun M, Yang JS, Xie M, Xu TP, Xia R, et al. Long noncoding RNA ANRIL promotes non-small cell lung cancer cell proliferation and inhibits apoptosis by silencing KLF2 and P21 expression. Mol Cancer Ther. 2015; 14(1):268-77. doi:10.1158/1535-7163.MCT-14-0492.

15. Pan W, Liu L, Wei J, Ge Y, Zhang J, Chen H, et al. A functional IncRNA HOTAIR genetic variant contributes to gastric cancer susceptibility. Mol Carcinog. 2016;55(1):90-6. doi:10.1002/mc.22261.

16. Pasmant E, Sabbagh A, Vidaud M, Bieche I. ANRIL, a long, noncoding RNA, is an unexpected major hotspot in GWAS. FASEB J. 2011;25(2):444-8. doi:10. 1096/fj.10-172452.

17. Ruigrok YM, Rinkel GJ. From GWAS to the clinic: risk factors for intracranial aneurysms. Genome Med. 2010;2(9):61. doi:10.1186/gm182.

18. Suo M, Lin Y, Yu H, Song W, Sun K, Song Y, et al. Association of Kallikrein gene polymorphisms with sporadic intracranial aneurysms in the Chinese population. J Neurosurg. 2014;120(6):1397-401. doi:10.3171/2013.11. JNS131036.

19. Wu SC, Kallin EM, Zhang Y. Role of H3K27 methylation in the regulation of IncRNA expression. Cell Res. 2010;20(10):1109-16. doi:10.1038/cr.2010.114.

20. Yasuno K, Bakircioglu M, Low SK, Bilguvar K, Gaal E, Ruigrok YM, et al. Common variant near the endothelin receptor type a (EDNRA) gene is associated with intracranial aneurysm risk. Proc Natl Acad Sci. 2011;108(49): 19707-12. doi:10.1073/pnas.1117137108.

21. Yasuno K, Bilguvar K, Bijlenga P, Low S, Krischek B, Auburger G, et al. Genome-wide association study of intracranial aneurysm identifies three new risk loci. Nat Genet. 2010;42(5):420-5. doi:10.1038/ng.563.

22. Ynte M, Ruigrok GJER. Genetics of intracranial aneurysms. Lancet Neurol. 2005:4(1):179-87.

23. Zhu Y, Li W, Ge M, Xu S, Zhao G, Wang H, et al. Polymorphism rs42524 of COL1A2 and sporadic intracranial aneurysms in the Chinese population. J Neurosurg. 2008;109(6):1060-4. doi:10.3171/JNS.2008.109.12.1060.

\section{Submit your next manuscript to BioMed Central and we will help you at every step:}

- We accept pre-submission inquiries

- Our selector tool helps you to find the most relevant journal

- We provide round the clock customer support

- Convenient online submission

- Thorough peer review

- Inclusion in PubMed and all major indexing services

- Maximum visibility for your research

Submit your manuscript at www.biomedcentral.com/submit 